Running head: GETTING PAST POST TRUTH

Letting the Gorilla Emerge From the Mist: Getting Past Post-Truth

\author{
Stephan Lewandowsky \\ University of Bristol and University of Western Australia \\ John Cook \\ George Mason University \\ Ullrich K. H. Ecker \\ University of Western Australia
}

Word count: XXXX excluding references (approximate count due to use of $\mathrm{ATE}_{\mathrm{E}}$ )

Stephan Lewandowsky

School of Experimental Psychology and Cabot Institute

University of Bristol

12a Priory Road

Bristol BS8 1TU, United Kingdom

stephan.lewandowsky@bristol.ac.uk

URL: http://www.cogsciwa.com 


\begin{abstract}
We welcome the 9 constructive and insightful commentaries on our target article. The commentaries proposed a number of creative, evidence-based applications of the principles we proposed. Here we identify common themes among the commentaries, including one relating to the political intentionality underlying much disinformation that we only partially addressed and that thus had remained shrouded in mist. We synthesize the suggestions from the commentary into a proposal that may help overcome the post-truth malaise, provided a final obstacle can be overcome. This obstacle is the gorilla in the room: Policy making in the United States is largely independent of the public's wishes but serves the interests of economic elites.
\end{abstract}


Getting past post truth 3

\section{Letting the Gorilla Emerge From the Mist: Getting Past Post-Truth}

At the time of this writing, questions about whether an hypothetical new strain of avian flu is contagious to humans would be resolved by medical research. Although the reliance on expertise and science in such matters appears obvious it need not be taken for granted: Our target article (Lewandowsky, Ecker, \& Cook, 2017, LEC from here on) raised the spectre of a dystopian "post-truth" future in which questions about viruses or the laws of physics are resolved not by "elitist" experts but by an opinion market on Twitter.

Although this possible future is still fictional, we argued that we already live in a "post-truth" era in which people's misconceptions can no longer be considered an isolated failure of individual cognition that can be corrected with appropriate communication tools. Instead, we argued that any response to the post-truth era must recognize the presence of widespread alternative epistemological communities that defy conventional standards of evidence. In those communities, climate change is seen as a hoax perpetrated by corrupt scientists, the Democratic party traffics child sex out of the basement of a pizza parlor in Washington D.C., and NASA is operating a slave colony on Mars.

Because those alternative epistemologies arguably arose as a consequence of societal mega-trends, such as growing inequality or the decline of social capital, we suggested that solutions to the post-truth crisis must also look beyond individual cognition. We proposed one avenue forward, based on the blending of insights from cognitive science with technology, an approach we called "technocognition."

Table 1 summarizes the 9 commentaries on LEC and identifies the code that we use to refer to individual contributions from here on. We structure our response around the main themes that emerged from the commentaries. 


\section{Cognition by the People and of the People}

Virtually all commentaries support our contention that the "post-truth" world is best understood as a phenomenon that goes beyond individual cognition and instead requires some form of collective analysis and understanding. Seifert put this elegantly: "The problem of misinformation 'in the head,' where individuals struggled to maintain inconsistent facts in memory, has been replaced by a problem of misinformation "in the world," where inconsistent information exists across individuals, cultures, and societies. Now, misinformation can be so 'good,' it is presented simply because it should be true ... (S, p. x).

There were, however, dissenting voices. At the most divergent end, RD focused entirely on individual-level cognition and made several helpful suggestions about how those can be harnessed for corrective efforts. We return to those suggestions later, but like the remaining commentators, we believe that the full social context must be considered before we can tackle processes based on individual cognition.

VB endorse our contextual approach but caution that the picture about politically-asymmetric susceptibility to misinformation is far from clear. VB acknowledge that there are some studies - which we cited; for example Pfattheicher and Schindler (2016) - that suggest that conservatives are more susceptible to being misled than liberals. However, they note that other studies show the opposite (e.g., Bakshy, Messing, \& Adamic, 2015). We agree that the issue is not fully settled. For example, there are some potential inconsistencies between the finding that conservatives exhibit greater credulity for information about hazards than liberals (Fessler, Pisor, \& Holbrook, 2017) on the one hand, and the well-established "white male" effect, which shows that white men (and in particular conservatives) downplay a number of risks (D. M. Kahan, Braman, Gastil, Slovic, \& Mertz, 2007). We are, however, quite confident that the rejection of scientific findings is mainly focused on the political right: the preponderance of survey and public 
opinion data supports this conclusion (Lewandowsky \& Oberauer, 2016). ${ }^{1}$ We are equally confident that overall, there is asymmetry between left and right on a multitude of cognitive variables (Jost, 2017), although it remains to be seen which of those variables are most pertinent to the post-truth world.

Filter Bubbles or People Filtering?

Commentators generally saw our proposal for "technocognition", that is cognitively-inspired design of information architectures that are more resilient to spreading misinformation, as providing a useful contribution, although some expressed skepticism that it was sufficient to act as a solution to the crisis For example, MD fear that technocognition would be "insufficient in countering systemic lies in the US" (MD, p. x), and HJ are concerned that triggering people's worldview defenses via technocognition (e.g., automated fact checking) may be counter-productive. Perhaps the most strident criticism was offered by Garrett, who disagreed with our uncritical acceptance of the ideas of echo chambers and filter bubbles (Pariser, 2011), and with the idea that techno-cognitive approaches could serve to break down those echo chambers and broaden filter bubbles. Garrett cites evidence that news audience fragmentation is, arguably, not as great as is often assumed (Flaxman, Goel, \& Rao, 2016). Indeed, some researchers argue that face-to-face interactions are more segregated now than online news consumption (Gentzkow \& Shapiro, 2011). To the extent that there is online segregation, it is said to be driven more by people's personal choices than algorithms (Bakshy et al., 2015).

We accept that if exposure is used as a metric, the fractionation of the information landscape may be less severe than some critics have feared. However, in line with Garrett's further comments, we believe that the crucial metric is engagement with content. The appearance of an item in one's Facebook news feed is of little consequence if it is ignored - what matters is whether it is read and processed. When engagement rather 
than exposure is considered, Garrett seems to be in agreement with us that the evidence for echo chambers is robust (Schmidt et al., 2017; Zollo et al., 2017).

The debate about whether exposure or engagement is the correct metric with which to approach echo chambers is not a mere intellectual curiosity. As Garrett notes, if exposure defined echo chambers, then a different form of technocognition would be needed to dilute them than if fractionation arose from engagement instead. He proceeds to propose a technocognitive approach aimed at engagement, namely modifications to Google's search algorithm so that they are sensitive not just to popularity but also to the accuracy of information. We agree, and we take up Garrett's suggestion in our concluding section that synthesizes the commentaries into a way forward.

\section{Demisting the Gorilla}

The focus of LEC was on identifying candidate societal trends that may have contributed to the emergence of a "post-truth" world. ${ }^{2}$ We identified 6 trends: (1) The decline of social capital, such as trust in institutions and civic engagement (e.g., Aldrich \& Meyer, 2015), accompanied by increasing social isolation (Sander \& Putnam, 2010). (2) Growing inequality (Sommeiller, Price, \& Wazeter, 2016) with its manifold adverse consequences (Wilkinson \& Pickett, 2009), including political polarization (Garand, 2010) and widespread discontent (Alesina \& Perotti, 1996). (3) Increasing political polarization, with levels of mutual animosity that can now exceed affective polarization over race (Iyengar, Van den Bulte, \& Valente, 2011). (4) Declining trust in science among Conservatives (but not Liberals; Gauchat, 2012). (5) An asymmetric credulity for misinformation that is greater among people on the political right than the left (e.g., Pfattheicher \& Schindler, 2016). (6) The increasing fractionation of the media landscape and the opportunity for "echo chambers" and "filter bubbles" it affords (e.g., Pariser, 2011). 
We acknowledged that this selection was largely arbitrary. We therefore do not insist that our selection of trends is exhaustive - on the contrary, we merely wanted to stimulate a growing conversation about the importance of the larger context in which individual cognition, such as responding to misinformation, takes place. In this spirit, we now offer a further mega-trend that we believe to be important and that we only became aware of after LEC was written. Santos, Varnum, and Grossmann (2017) provided comprehensive cross-national evidence for a global increase in individualism, measured in both attitudes and practices, during the last 30-40 years. Individualism is "a view of the self as self-directed, autonomous, and separate from others", and it stands in contrast to collectivism, which refers to an "interconnected view of the self that overlaps with close others, with individuals' thoughts, feelings, and behaviors embedded in social contexts" (Santos et al., 2017, p. 3). There is much evidence that individualism is a principal driver of the rejection of several well-established scientific propositions, foremost among them climate change (see, e.g., D. Kahan, 2016). The increasing global individualism might therefore be reason for concern, not because individualism is inherently "wrong", but because it provides a fertile milieu for the rejection of at least some evidence-based policies.

The enumeration of societal trends, however, can only take us so far towards understanding the emergence of the post-truth world. This limitation was recognized by several commentators who did not hesitate to highlight the instrumental background to the post-truth malaise that we only hinted at: The post-truth crisis is not some random natural (or societal) calamity, but it has been carefully curated and stoked by political operatives and vested interests. MD are perhaps most outspoken when they point to the "intentional promotion of misinformation in the powerful conservative echo chamber, ranging from the conspiracy theories of Infowars and Rush Limbaugh to the consistent lies and exaggerations about liberal politicians and Democratic candidates spread on Fox 
News, Breitbart, and talk radio" (MD, p. x). The importance of disinformation was also echoed by Garrett, Seifert, HJ, and WJ.

We agree entirely with those comments, notwithstanding their inevitable political overtones. As we noted in LEC, "science sometimes cannot help but be political: for example, the potential political fallout must not deter medical researchers from determining, and then publicly articulating, that smoking causes lung cancer" (Lewandowsky et al., 2017, p. x). Indeed, in the fast-moving world in which we are writing, we would now consider it ethically problematic to ignore or withhold relevant evidence about political developments. For example, we must not ignore the evidence that the "Tea Party" in the U.S. was not a spontaneous eruption of "grassroots" opposition to former President Obamas healthcare initiative but the result of long-standing efforts by libertarian and conservative "think tanks" and political operatives (Mayer, 2016). We must not be blind to the fact that Donald Trump learned his trade from Sen. Joe McCarthy's chief counsel who was the brains behind the paranoid hunt for communist infiltrators in the 1950s (O'Harrow \& Boburg, 2016). We must recognize that the xenophobia and Islamophobia (Swami, Barron, Weis, \& Furnham, 2017) that contributed to the Brexit vote was fostered by the U.K. tabloid press. Four outlets, The Sun, Daily Mail, Daily Express, and Daily Star, ran more than 8,000 stories about asylum seekers - many of them inflammatory - in the period from 2000-2006 alone, with more than 1,400 of those articles using the terms "immigrant" and "asylum-seeker" interchangeably (Colville, 2016).

We therefore conclude with a synthesis of the recommendations in the comments that does not shy away from recognition of the political context in which we live. 
Getting past post truth 9

\section{A Synthesis}

We agree with MD that it is essential to differentiate between different types of misinformation. We find their classification of misinformation into four distinct categories helpful, although we are less convinced by MD's attempts to arrange those four categories within the two axes of a two-dimensional space. For example, it is difficult to see why "truthiness", which MD define as an "emotional, non-cognitive form of radical constructivism" (MD, p. $\mathrm{x}$ ), is located at the "strong realism" end of an axis whose opposite pole is "strong constructivism".

We also propose that MD's classification would benefit from the addition of a further category, which we call "paltering". Paltering is a technique of deception that stops short of literal falsity (Schauer \& Zeckhauser, 2009). For example, rhetorical claims made to deny climate change (e.g., "sea levels have fallen in the last 2 years") are often literally true but nonetheless highly deceptive (because sea level rise continues unabated notwithstanding small fluctuations about the trend line). The deceptions are readily revealed when the full context is provided (Lewandowsky, Ballard, Oberauer, \& Benestad, 2016). Our proposed paltering category largely overlaps with the concern raised by WJ about subtle, slanted misinformation that defies identification by automated tools. Table 2 summarizes the resulting 5 categories of misinformation and how they might be met. The putative countermeasures in the table draw on proposals from all commentaries. Those countermeasures are to be understood as additions to conventional fact checking and public corrections, which must continue - if only for obvious ethical reasons - notwithstanding their limited efficacy.

BC's commentary focused on the importance of the elites - that is, politicians, media organizations and opinion leaders, think tanks, and so on-in creating the post-truth problem. In support, Brulle, Carmichael, and Jenkins (2012) found that shifts in U.S. public attitudes on climate change (from 2002 to 2010) were largely driven by elite 
cues, in particular the Republican leadership's withdrawal from the scientific consensus. Fortunately, there is evidence that elites are sensitive to being held to account. In an elegant experiment involving state legislators, Nyhan and Reifler (2015) showed that legislators are sensitive to the reputational consequences of questionable public statements. A randomly selected group of legislators were sent letters about the risks to their reputation and electoral chances if their public statements were identified as being questionable. This group was substantially less likely to make inaccurate public statements in an ensuing election than legislators in a control condition who were not threatened with the consequences of fact checking. Holding elites to account - or the mere threat of such accountability - therefore demonstrably works in at least some circumstances. However, this technique is unlikely to be effective in situations where the intent is to disrupt or to create an alternative epistemological community (Shock \& chaos and Truthiness in Table 2).

Garrett suggests that the solution to post-truth must involve a new set of gate keepers that can replace the editorial control that used to be exercised by newspaper editors. We agree that such automated gate-keeping - e.g., the introduction of a factual-accuracy component to Google searches - may be necessary in order to deal with many forms of misinformation, foremost among them Bullshit and Shock \& Chaos. However, the design of any such automated tools must be sensitive to the conception of democracy it entails. In a thoughtful analysis Bozdag and van den Hoven (2015) showed how different technological tools are tacitly built on different conceptions of democracy. For example, tools that allow users control over incoming information and filters are tacitly built on the idea of a liberal democracy, whereas tools that seek to increase the epistemic quality and breadth of information are endorsing a deliberative conception of democracy. Seifert's list of sites that can help users step outside their filter bubble (e.g., "Escape Your Bubble"; https://www.escapeyourbubble.com/, "Red Feed, Blue Feed"; 
http://graphics.wsj.com/blue-feed-red-feed/, "FlipFeed";

https://flipfeed.media.mit.edu/, or "PolitEcho"; http://politecho.org/) is therefore steeped in a deliberative view of democracy.

It is likely that automated gate-keeping and other techno-cognitive tools will be particularly challenged by Paltering and Truthiness, and to a lesser extent, by Systemic lies: Common to those forms of misinformation is their ostensible commitment to realism. Climate denial, for example, typically masquerades as "pro-science" skepticism and paints the actual science of climate change as being "corrupt" or "post-modern." It is possible that those carefully-crafted forms of misinformation will require continued human debunking as well as increased media literacy.

The idea of media and information literacy was central to the commentaries by VB and MY. We agree that media literacy, that is the public's ability to discern reliable from unreliable information, should be foregrounded in education. Encouraging results have been obtained in classroom settings (e.g., Walton \& Hepworth, 2011). It is also encouraging that greater knowledge about the news media has been found to be associated with a reduced propensity to endorse various conspiracy theories, even when those theories were aligned with participants' political worldviews (Craft, Ashley, \& Maksl, 2017).

However, information literacy is a nuanced concept and is unlikely to be a panacea. MY make the valuable point that literacy skills must extend beyond merely evaluating source credibility. MY correctly assert that "typical cues for credibility have been hijacked, making source evaluation increasingly difficult" (MY, p. x), as exemplified by middle school students' inability to identify an item as advertising when it was presented as "sponsored content." Nonetheless, several recent studies have shown that people can be "inoculated" against misinformation if they are informed of specific disinformation techniques ahead of time (Cook, Lewandowsky, \& Ecker, 2017; van der Linden, Leiserowitz, Rosenthal, \& Maibach, 2017). 
Enhancing media and information literacy is not without its own problems, however. If media literacy becomes focused on "critical thinking" alone, it may inadvertently make people more cynical and less trustful of media and institutions overall (Mihailidis \& Viotty, 2017). We therefore embrace the suggestion by MY that people ought to be assisted in the recognition of weak arguments, irrespective of a source's credibility. One particularly weak form of argumentation rests on incoherence. We have recently shown that the rhetoric of climate denial is inherently incoherent (Lewandowsky, Cook, \& Lloyd, 2016). It remains to be seen how readily people can be taught to recognize incoherence (e.g., "Global temperature cannot be measured with any degree of accuracy. It is quite clear that the Earth hasn't warmed in the last 5 years."). It also remains to be seen whether detection of incoherence, in turn, has any effect on people's susceptibility to denialist arguments. There are signs that such interventions may be successful. RB pointed to studies showing that corrections can be effective when people become aware that information is implausible (Hinze, Slaten, Horton, Jenkins, \& Rapp, 2014), or when pithy explanations are presented to refute one view and affirm another (Ranney \& Clark, 2016).

Information literacy may, however, be insufficient to overcome the strong effects of worldview on people's responses to misinformation and its correction. HJ recognize the importance of worldview in information processing and in particular in the resistance to correction of misconceptions (e.g., Nyhan \& Reifler, 2010). HJ also suggest that "we must address both the misinformation and the worldviews leading to the acceptance of that misinformation." (HJ, p. x). This recommendation deserves to be carefully unpacked because we doubt it would be advisable or permissible to exhort someone to be "less conservative" or "more open-minded." Political worldviews are an individual's prerogative and should not be targeted by corrective efforts. However, when it comes to worldviews of "not [valuing] empirical evidence and [...] not [trusting] scientists and other experts", we 
believe that it is acceptable to educate people about the problems inherent in those views. Science education and science engagement activities may change these worldviews and increase trust in science.

In seeming opposition to our view, HJ "doubt it will be possible to sneak true but inconsistent information past someone's activated worldview" (HJ, p. x). However, this mis-characterizes our position, which is that worldview and factual information need to be decoupled from each other, for example by reframing an issue. HJ go on to propose that worldviews are multi-faceted and contextualized (Oyserman \& Schwarz, 2017; Unsworth \& Fielding, 2014), arguing that people "may activate different identities depending on the current situation, changing the way they interact with the world" (HJ, p. x). This aligns quite well with our preferred approach to reframe an issue so different aspects of a worldview are triggered. In the case of climate change this might involve highlighting the effects of climate change (and mitigation) on public health (Maibach, Nisbet, Baldwin, Akerlof, \& Diao, 2010) or highlighting that the economic cost of mitigation is small compared to projected future wealth increases (Hurlstone, Lewandowsky, Newell, \& Sewell, 2014).

Finally, WJ advocate "the building of close relationships between science and society, scientists and citizens, in order to produce outcomes of innovation that align with societal goals and values." This idea is meritorious, and indeed there are successful cases of knowledge co-production between citizens and scientists (e.g., Whatmore \& Landström, 2011) but the idea that tech giants such as Facebook would substantively amend their algorithms to prioritize societal benefit over profits as a result of dialogue with citizens appears overly optimistic to us. On the contrary, Facebook has recently expressed opposition to German laws aimed at forcing tech giants to remove hate speech within 24 hours or face substantial fines (Shead, 2017). Which brings us to the gorilla in the room. 
The gorilla

What determines the outcome of political debates in the United States? A quantitative analysis of the underlying variables was provided by Gilens and Page (2014) based on an analysis of 1,779 policy issues decided by the U.S. government between 1981 and 2002. Figure 1 shows their results. The dashed gray line shows the likelihood of a policy measure being adopted as a function of public opinion, and the solid black line shows the likelihood of adoption as a function of economic elite opinion. If the public is nearly united against a policy, it has a probability of adoption of around $30 \%$. If the public is nearly united in supporting a policy, that probability is also around $30 \%$. By contrast, if the economic elites oppose a measure, the probability of its adoption is near zero, and it rises to $60 \%$ or more when the elites strongly support it. Gilens and Page (2014) dryly conclude that "The results provide substantial support for theories of Economic-Elite Domination and for theories of Biased Pluralism, but not for theories of Majoritarian Electoral Democracy or Majoritarian Pluralism" (p. 564).

In the present context, those data imply that any response to the post-truth malaise that involves legislation or policy - as many techno-cognitive initiatives might - is unlikely to be successful unless it is supported by economic forces. We are not aware of any support for corrective legislation among the tech giants, such as Apple, Amazon, Facebook, and Google. On the contrary, at the time of this writing, Donald Trump has co-opted the term "fake news" in his attacks on the media, going so far as to claim that he invented the term himself (Cillizza, 2017). This suggests that widespread public and academic concern about the "post-truth" world is unlikely to result in any legislative change.

We are left with a better understanding of the post-truth world and how we got here. We can also imagine solutions that are inspired by cognitive research and can be combined with new technologies. All we need to do now, is deal with the 800 pound 
Getting past post truth 15

gorilla in the room - namely, a political system that is driven by the interests of economic elites rather than the people. 


\section{References}

Aldrich, D. P., \& Meyer, M. A. (2015). Social capital and community resilience. American Behavioral Scientist, 59, 254-269. doi: 10.1177/0002764214550299

Alesina, A., \& Perotti, R. (1996). Income distribution, political instability, and investment. European Economic Review, 40, 1203 - 1228. doi: $10.1016 / 0014-2921(95) 00030-5$

Bakshy, E., Messing, S., \& Adamic, L. (2015). Exposure to ideologically diverse news and opinion on Facebook. Science. doi: 10.1126/science.aaa1160

Boussalis, C., \& Coan, T. G. (2017). Elite polarization and correcting misinformation in the "post-truth era". Journal of Applied Research in Memory and Cognition.

Bozdag, E., \& van den Hoven, J. (2015). Breaking the filter bubble: democracy and design. Ethics and Information Technology, 17, 249-265. doi:

$10.1007 / \mathrm{s} 10676-015-9380-\mathrm{y}$

Brulle, R. J., Carmichael, J., \& Jenkins, J. C. (2012). Shifting public opinion on climate change: an empirical assessment of factors influencing concern over climate change in the U.S., 2002-2010. Climatic Change, 114, 169-188. doi:

$0.1007 / \mathrm{s} 10584-012-0403-\mathrm{y}$

Cillizza, C. (2017). Donald Trump just claimed he invented 'fake news'. Retrieved from http://edition.cnn.com/2017/10/08/politics/trump-huckabee-fake/index.html

Colville, R. (2016). Words and images. UNHCR Refugees(142), 14-17.

Cook, J., Lewandowsky, S., \& Ecker, U. K. H. (2017). Neutralizing misinformation through inoculation: Exposing misleading argumentation techniques reduces their influence. PLOS ONE, 12, e0175799. doi: 10.1371/journal.pone.0175799

Craft, S., Ashley, S., \& Maksl, A. (2017). News media literacy and conspiracy theory endorsement. Communication and the Public. doi: 10.1177/2057047317725539 
Fessler, D. M. T., Pisor, A. C., \& Holbrook, C. (2017). Political orientation predicts credulity regarding putative hazards. Psychological Science, 28, 651-660.

Flaxman, S., Goel, S., \& Rao, J. M. (2016). Filter bubbles, echo chambers, and online news consumption. Public Opinion Quarterly, 80, 298 - 320.

Garand, J. C. (2010). Income inequality, party polarization, and roll-call voting in the U.S. Senate. The Journal of Politics, 72, 1109-1128. doi: 10.1017/S0022381610000563

Garrett, R. K. (2017). The "echo chamber" distraction: Disinformation campaigns are the problem, not audience fragmentation. Journal of Applied Research in Memory and Cognition.

Gauchat, G. (2012). Politicization of science in the public sphere: A study of public trust in the United States, 1974 to 2010. American Sociological Review, 77, 167-187.

Gentzkow, M., \& Shapiro, J. M. (2011). Ideological segregation online and offline. Quarterly Journal of Economics, 126, 1799-1839. doi: 10.1093/qje/qjr044

Gilens, M., \& Page, B. I. (2014). Testing theories of American politics: Elites, interest groups, and average citizens. Perspectives on Politics, 12, 564-581.

Hinze, S. R., Slaten, D. G., Horton, W. S., Jenkins, R., \& Rapp, D. N. (2014). Pilgrims sailing the Titanic: Plausibility effects on memory for misinformation. Memory $\mathbb{E}$ Cognition, 42, 1-20. doi: 10.3758/s13421-013-0359-9

Hurlstone, M. J., Lewandowsky, S., Newell, B. R., \& Sewell, B. (2014). The effect of framing and normative messages in building support for climate policies. PLOS ONE, 9, e114335. doi: 10.1371/journal.pone.0114335

Hyman, I. E., \& Jalbert, M. C. (2017). Misinformation and worldviews in the post-truth information age: Commentary on lewandowsky, ecker, and cook. Journal of Applied Research in Memory and Cognition.

Iyengar, R., Van den Bulte, C., \& Valente, T. W. (2011). Opinion leadership and social contagion in new product diffusion. Marketing Science, 30, 195-212. doi: 
$10.1287 / \mathrm{mksc} .1100 .0566$

Jost, J. T. (2017). Ideological asymmetries and the essence of political psychology. Political Psychology, 38, 167-208. doi: 10.1111/pops.12407

Kahan, D. (2016). The politically motivated reasoning paradigm. Emerging Trends in Social $\&$ Behavioral Sciences, in press.

Kahan, D. M., Braman, D., Gastil, J., Slovic, P., \& Mertz, C. K. (2007). Culture and identity-protective cognition: Explaining the white-male effect in risk perception. Journal of Empirical Legal Studies, 4, 465-505.

Kloor, K. (2012, September). GMO opponents are the climate skeptics of the left (http://www.slate.com/articles/health_and_science/science/2012/09/ are_gmo_foods_safe_opponents_are_skewing_the_science_to_scare_people_html).

Retrieved from

http://www.slate.com/articles/health_and_science/science/2012/09/ are_gmo_foods_safe_opponents_are_skewing_the_science_to_scare_people_.html (Accessed 29 September 2012)

Lewandowsky, S., Ballard, T., Oberauer, K., \& Benestad, R. (2016). A blind expert test of contrarian claims about climate data. Global Environmental Change, 39, 91-97. Lewandowsky, S., Cook, J., \& Lloyd, E. (2016). The 'Alice in Wonderland' mechanics of the rejection of (climate) science: simulating coherence by conspiracism. Synthese. doi: 10.1007/s11229-016-1198-6

Lewandowsky, S., Ecker, U. K. H., \& Cook, J. (2017). Beyond misinformation: Understanding and coping with the post-truth era. Journal of Applied Research in Memory and Cognition, in press.

Lewandowsky, S., \& Oberauer, K. (2016). Motivated rejection of science. Current Directions in Psychological Science, 25, 217-222.

Maibach, E., Nisbet, M., Baldwin, P., Akerlof, K., \& Diao, G. (2010). Reframing climate 
change as a public health issue: an exploratory study of public reactions. $B M C$ Public Health, 10, 299.

Marsh, E. J., \& Yang, B. W. (2017). A call to think broadly about information literacy: Comment on "beyond misinformation: Understanding and coping with the post-truth era" by lewandowsky, ecker, \& cook. Journal of Applied Research in Memory and Cognition.

Mayer, J. (2016). Dark money: The hidden history of the billionaires behind the rise of the radical right. Scribe Publications.

McCright, A. M., \& Dunlap, R. E. (2017). Combatting misinformation requires recognizing its types and the factors that facilitate its spread and resonance. Journal of Applied Research in Memory and Cognition.

Mihailidis, P., \& Viotty, S. (2017). Spreadable spectacle in digital culture: Civic expression, fake news, and the role of media literacies in post-fact society. American Behavioral Scientist, 61, 441-454. doi: 10.1177/0002764217701217

Mooney, C. (2011, June). The science of why we don't believe science (http://motherjones.com/politics/2011/03/denial-science-chris-mooney). Retrieved from http://motherjones.com/politics/2011/03/denial-science-chris-mooney?page=1 (Accessed 21 December 2011)

Nyhan, B., \& Reifler, J. (2010). When corrections fail: The persistence of political misperceptions. Political Behavior, 32, 303-330.

Nyhan, B., \& Reifler, J. (2015). The effect of fact-checking on elites: A field experiment on U.S. state legislators. American Journal of Political Science, 59, 628-640. doi: 10.1111/ajps.12162

O'Harrow, R. O., \& Boburg, S. (2016). The man who showed Donald Trump how to exploit power and instill fear. Retrieved from 
https://www . washingtonpost. com/investigations/former-mccarthy-aide-showed-trump-how-to2016/06/16/e9f44f20-2bf3-11e6-9b37-42985f6a265c_story.html

Oyserman, D., \& Schwarz, N. (2017). Conservatism as a situated identity: Implications for consumer behavior. Journal of Consumer Psychology, 27, 532 - 536. doi: https://doi.org/10.1016/j.jcps.2017.08.003

Pariser, E. (2011). The filter bubble: What the internet is hiding from you. New York: Penguin Press.

Pfattheicher, S., \& Schindler, S. (2016). Misperceiving bullshit as profound is associated with favorable views of Cruz, Rubio, Trump and conservatism. PLoS ONE, 11, e0153419. doi: 10.1371/journal.pone.0153419

Ranney, M. A., \& Clark, D. (2016). Climate change conceptual change: Scientific information can transform attitudes. Topics in Cognitive Science, 8, 49-75. doi: $10.1111 /$ tops. 12187

Rapp, D. N., \& Donovan, A. M. (2017). Routine processes of cognition result in routine influences of inaccurate content. Journal of Applied Research in Memory and Cognition.

Sander, T. H., \& Putnam, R. D. (2010). Still bowling alone?: The post-9/11 split. Journal of Democracy, 21, 9-16.

Santos, H. C., Varnum, M. E., \& Grossmann, I. (2017). Global increases in individualism. Psychological Science.

Schauer, F., \& Zeckhauser, R. (2009). Paltering. In B. Harrington (Ed.), Deception: From ancient empires to internet dating (pp. 38-54). Stanford, CA: Stanford University Press.

Schmidt, A. L., Zollo, F., Del Vicario, M., Bessi, A., Scala, A., Caldarelli, G., ... Quattrociocchi, W. (2017). Anatomy of news consumption on Facebook. Proceedings of the National Academy of Sciences, 114, 3035-3039. doi: 
$10.1073 /$ pnas. 1617052114

Seifert, C. M. (2017). The distributed influence of misinformation. Journal of Applied Research in Memory and Cognition.

Shead, S. (2017). Facebook said Germany's plan to tackle fake news would make social media companies delete legal content. Retrieved from http://uk.businessinsider.com/facebook-says-germany-fake-newsplans-comply-with-eu-law-2017-5

Shermer, M. (2013, January). The liberals' war on science (http://www.scientificamerican.com/article.cfm?id=the-liberals-war-on-science). Retrieved from http://www.scientificamerican.com/ article.cfm?id=the-liberals-war-on-science (Accessed 28 January 2013) Sommeiller, E., Price, M., \& Wazeter, E. (2016). Income inequality in the US by state, metropolitan area, and county (Tech. Rep.). Economic Policy Institute.

Swami, V., Barron, D., Weis, L., \& Furnham, A. (2017). To Brexit or not to Brexit: The roles of Islamophobia, conspiracist beliefs, and integrated threat in voting intentions for the United Kingdom European Union membership referendum. British Journal of Psychology. doi: 10.1111/bjop.12252

Unsworth, K. L., \& Fielding, K. S. (2014). It's political: How the salience of one's political identity changes climate change beliefs and policy support. Global Environmental Change, 27, 131-137.

van der Linden, S., Leiserowitz, A., Rosenthal, S., \& Maibach, E. (2017). Inoculating the public against misinformation about climate change. Global Challenges, 1, 1600008. doi: $10.1002 /$ gch2.201600008

Vraga, E. K., \& Bode, L. (2017). Leveraging institutions, educators, and networks to correct misinformation: A commentary on lewandowsky, ecker, and cook. Journal of Applied Research in Memory and Cognition. 
Walton, G., \& Hepworth, M. (2011). A longitudinal study of changes in learners' cognitive states during and following an information literacy teaching intervention. Journal of Documentation, 67, 449-479.

Webb, H., \& Jirotka, M. (2017). Commentary on "beyond misinformation: Understanding and coping with the post truth era". Journal of Applied Research in Memory and Cognition.

Whatmore, S. J., \& Landström, C. (2011). Flood apprentices: an exercise in making things public. Economy and Society, 40, 582-610. doi: $10.1080 / 03085147.2011 .602540$

Wilkinson, R., \& Pickett, K. (2009). The spirit level : why more equal societies almost always do better. London: Allen Lane.

Zollo, F., Bessi, A., Del Vicario, M., Scala, A., Caldarelli, G., Shekhtman, L., ... Quattrociocchi, W. (2017). Debunking in a world of tribes. PLOS ONE, 12, e0181821. doi: 10.1371/journal.pone.0181821 
Getting past post truth 23

\begin{abstract}
Author Note
Preparation of this paper was facilitated by a Wolfson Research Merit Award from the Royal Society to the first author and a Discovery Grant from the Australian Research Council to the third and first author. Address correspondence to the first author at the Department of Experimental Psychology and Cabot Institute, University of Bristol, 12a Priory Road, Bristol BS8 1TU, United Kingdom. email: stephan.lewandowsky@bristol.ac.uk. Personal web page: http://www.cogsciwa.com.
\end{abstract}


Getting past post truth 24

\section{Footnotes}

1 VB suggest that the selection of scientific issues we put forward was biased against conservatives. This is not the case. At least two of the issues, vaccinations and genetically-modified organisms, had been anecdotally—but erroneously — thought to be subject to denial by the political left (Kloor, 2012; Mooney, 2011; Shermer, 2013).

2 Our analysis was mainly focused on the United States and it remains to be seen how many of those trends are also manifest elsewhere. 
Table 1

Summary of commentaries on the target article by Lewandowsky, Ecker, 86 Cook (2017)

\begin{tabular}{|c|c|c|}
\hline Citation & Code & Synopsis \\
\hline Boussalis \& Coan (2017) & $\mathrm{BC}$ & $\begin{array}{l}\text { The role of elites was crucial in creating the problem } \\
\text { but will also be crucial in solving it. }\end{array}$ \\
\hline Garrett (2017) & G & $\begin{array}{l}\text { Disinformation campaigns, not echo chambers, are the } \\
\text { real problem. }\end{array}$ \\
\hline Hyman \& Jalbert (2017) & HJ & $\begin{array}{l}\text { We must address the worldviews that lead to the } \\
\text { acceptance of misinformation. }\end{array}$ \\
\hline Marsh \& Yang (2017) & MY & We must foster information literacy. \\
\hline McCright \& Dunlap (2017) & MD & $\begin{array}{l}\text { Misinformation is intentionally promoted by a } \\
\text { powerful conservative echo chamber. }\end{array}$ \\
\hline Rapp \& Donovan (2017) & $\mathrm{RD}$ & $\begin{array}{l}\text { Drawing attention to implausibility or providing } \\
\text { refutation-based explanations can correct }\end{array}$ \\
\hline Seifert (2017) & S & $\begin{array}{l}\text { misinformation. } \\
\text { The problem of misinformation used to be "in the } \\
\text { head" but it is now "in the world." }\end{array}$ \\
\hline Vraga \& Bode (2017) & $\mathrm{VB}$ & $\begin{array}{l}\text { Media literacy training must be taken out of the } \\
\text { classroom. }\end{array}$ \\
\hline Webb \& Jirotka (2017) & WJ & $\begin{array}{l}\text { We need to understand the different types of } \\
\text { misinformation. }\end{array}$ \\
\hline
\end{tabular}


Getting past post truth 26

Table 2

Categories of misinformation (1-4 are taken from MD's classification) and potential countermeasures

\begin{tabular}{lll}
\hline \multirow{2}{*}{ Category } & \multicolumn{1}{c}{ Synopsis } & \multicolumn{1}{c}{ Countermeasure } \\
\hline \multirow{2}{*}{ Truthiness } & Emotional constructivism (e.g., Sean & Information literacy, \\
& Hannity) & dilution of echo chambers \\
Bullshit & Cavalier disrespect for reason (e.g., & Automated detection, \\
& Infowars) & dilution of echo chambers, \\
& & gate keepers \\
Systemic lies & Carefully curated campaigns in support & Elite accountability, \\
& of an agenda (e.g., climate denial) & automatic detection tools, \\
& & information literacy \\
Shock \& chaos & Misinformation intended to destabilize & Information literacy, \\
& social relations and societal institutions & automatic detection tools, \\
& (e.g., Russian twitter bots) & gate keepers \\
& Deception that avoids falsity (e.g., & Elite accountability, \\
& climate denial, politicians) & information literacy \\
\hline & &
\end{tabular}




\section{Figure Captions}

Figure 1. Predicted probability of policy adoption in the United States as a function of opinion among citizens (dashed line) and economic elites (solid lines). Data from Gilens \& Page (2014). See text for details. 
Getting past post truth, Figure 1

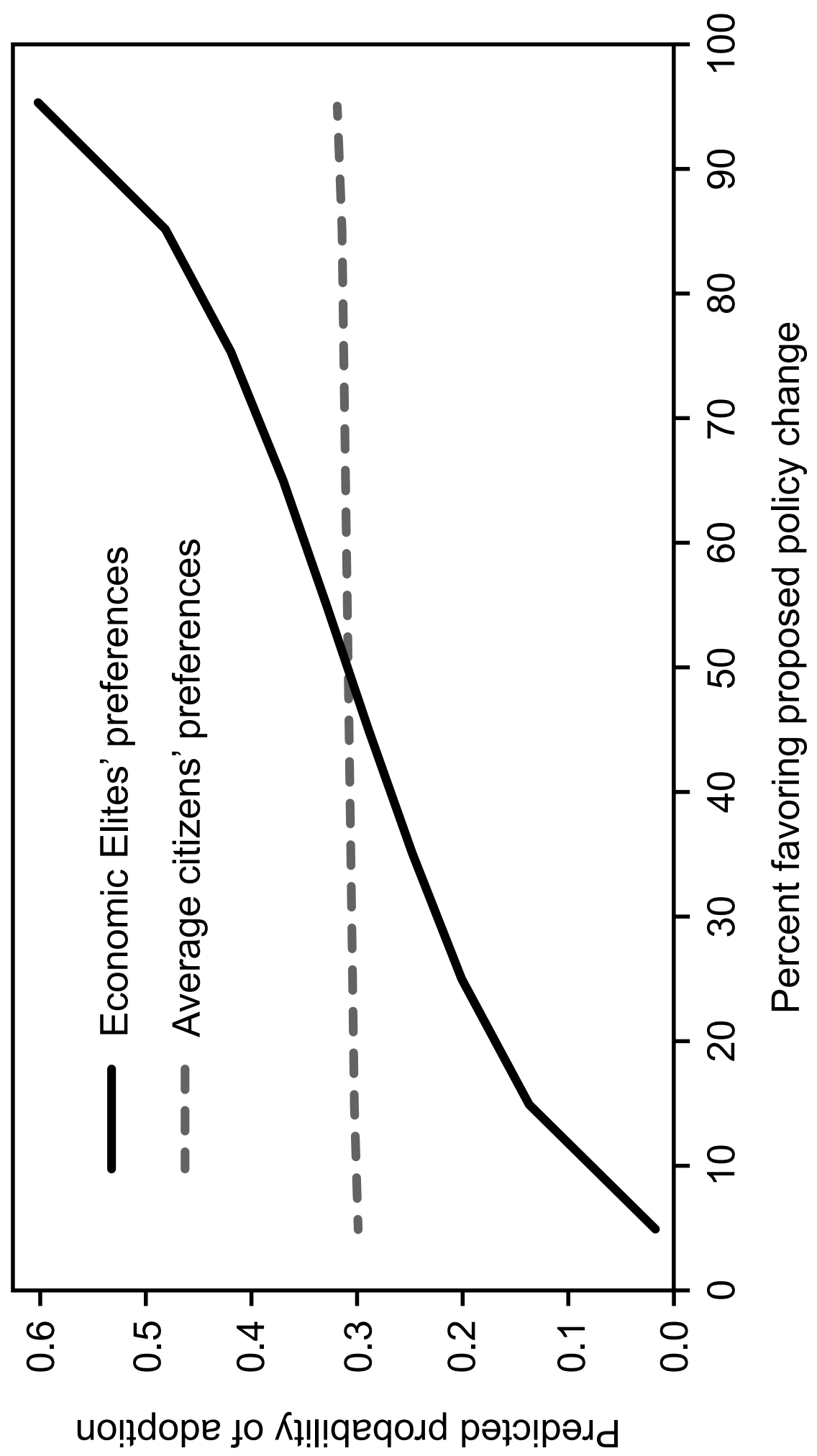

